\title{
Innovative mining technologies with complex geomechanical characteristics
}

\author{
Dimitar Anastasov ${ }^{1, *}$, and Zdravets Eftimov ${ }^{1}$ \\ ${ }^{1}$ University of Mining and Geology „St. Ivan Rilski“, Department of Mining of Mineral Deposits, Studentski Grad, “prof. Boyan \\ Kamenov" Street, Sofia 1700, Bulgaria
}

\begin{abstract}
The article presents innovative technologies for the extraction of minerals from underground mines with complex geological, mining, and technical and geomechanical characteristics. The need to develop such mining technologies is discussed and the conditions under which they should be applied are presented. Principal variants of extraction technologies such as Raisebor technology, Raisebor technology in combination with the drilling and blasting method and the continuous development system using Alimak or KOV - 25 monorail complex are shown in the article.
\end{abstract}

\section{The need to develop new technologies}

The development of the technologies for mineral processing leads to significant improvement of technical, technological and economic indicators of the overall production. It is possible to process low-grade ores, develop deposits with more complex geomechanical characteristics and achieve a positive economic result. This situation in the mining industry is also helped by the gradual but continuous increase of the prices of the end products produced over the last 15-20 years.

Hence, reassessment of the reserves and adjustments in the commercially useful components in the extracted raw materials are necessary.

Thus, an increase in the amount of reserves is achieved, both in existing mines and in newly created ones. In addition, a certain extension of the operational time of existing mines is also achieved by re-categorizing reserves. Conditions are also being created for the development of new mineral deposits considered to be not very promising (with non-minable contents of useful components).

All this sets up preconditions for creating opportunities for the development of deposits with complex geological, morphological, mining, technical and geomechanical characteristics during the operation of underground mines.

As it is well-known, in the underground mining of complex-structured deposits the classical systems of development are the sublevel stoping method of mining and the square-set stoping-and-filling method of mining with Alimak technology and subsequent mass drawing and caving.

The variants of the sublevel stoping method of mining of deposits with low strength indicators are characterised in two directions: with light portable mechanisation or with mobile mechanisation and front recovery of the ore.
In order to do this, a network of opening access roads and inclined development workings for the mining equipment is created. [1] The recovery ratio is 0.9 and the contamination factor is 15 to $20 \%$.

The application of the square-set stoping-and-filling method is universal for this type of deposits and it is characterised by low economic efficiency due to the external production processes such as the support and the filling of the mined-out area. The variants are supports with $3 / 4$ wooden frames and wooden lining of the stope or roof bolting with a metal net combined with shotcrete. A high recovery ratio of 0,95 to 0,98 and minimum contamination factor from 3 to $5 \%$ are typical for these variants. The Alimak technology is also applicable in complex-structured deposits with shrinkage of the ore. The variant of this technology with open chambers (continuous system) for ore bodies with high dip is not applicable and the caving method of mining of the bedding rocks is used.

In the variants with sublevel caving and the Alimak Technology certain deformations of the surfaces of deposits are admissible which requires additional resources for the reclamation of the damaged lands. The Raisebor technology is used for the extraction of uranium in Canada (Cameco Corporation) [2]. Similar systems have been also described for the development of complexstructured rich iron deposits. [3]

It is important to define correctly the parameters of blasting works, taking into consideration the strain and stress condition of the rock mass when applying these systems for development. [4]

\footnotetext{
* Corresponding author: danast@mgu.bg
} 


\section{Conditions for the applicability of innovative ore mining technologies in deposits with complex geomechanical characteristics}

Innovative technologies for the extraction of minerals are increasingly used in the mining practice for the development of deposits with complex morphology, complex geomechanical characteristics and high value of the mineral resources. The adjusting and reworking of existing development systems and extraction technologies to specific conditions is aimed at finding a solution to a particular problem in a given deposit and not at creating conventional technologies for mass application.

These innovative technologies should be applied in the development of new deposits with complex geological, mining, technical and geomechanical characteristics (ore bodies with complex morphology, illdefined boundaries, weak ore and host rock strengths, high temperature, etc.), and high value of the extracted raw material.

The objective of developing innovative mining technologies for deposits with complex mining, technical and geomechanical characteristics is to find out a new solution for optimizing yield results. This new engineering solution must be different from the conventional methods of extraction, whereby we will have a positive economic effect (as opposed to classical methods of extraction) from the development of a given deposit.

\section{Raisebor technology}

The Raisebor technology consists of extracting vertical layers (rises) from the ore body in a specific order, with the mined out spaces being filled. [5,6] The primary chambers are filled with a paste-hardening fill to achieve sufficient camera strength to open a secondary chamber next to the filled rock mass without leaving pillars [7]. The secondary chambers can be filled both with a pastehardening fill and a rock-fill from a sterile mass obtained during the driving of the mining workings.

The purpose of developing a Raisebor technology is to provide a productive mining technology applied in complex morphological and geomechanical conditions. Thus, the loss and impoverishment indicators of the raw materials extracted (without pillar recovery) are reduced. [8].

On the other hand, the technology is designed in such a way so that during the whole stage of operation, the ore extraction is carried out without the presence of people in the mining areas. This ensures safety at work due to the absence of people in the mining areas, as well as the reduction of additional processes for the maintenance of mining areas, ventilation, etc.

Raisebor technology makes it possible to mine ore bodies with complex morphology and ill-defined boundaries. Ore bodies with an average thickness of 0.7 $2.5 \mathrm{~m}$ and an angle of inclination from $90^{\circ}$ - to $60^{\circ}$ can be mined out. This mining method can be applied to bodies with complex morphology both for the overall development of an underground mine and for its individual sections.
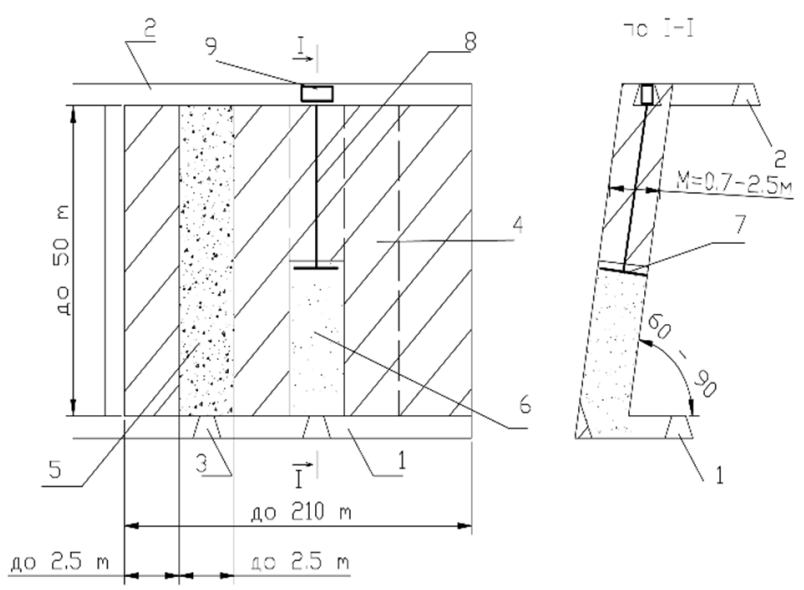

Fig. 1. Raisebor technology for mining of mineral resources Legend: 1 - haulage level; 2 - air drift; 3 - loading cut-off entries; 4 - ore body; 5 - paste-hardening fill; 6 - fines, extracted ore; 7 - cutting head; 8 - borehole; 9 - Raisebor machine.

The technology offers several options for mining-out: A - Using stationary mechanization:

- Standard - a pilot hole, which expands from the bottom up, is drilled. This method is characterized by a maximum diameter of the side cutting of up to $6 \mathrm{~m}$ and a maximum depth of $1000 \mathrm{~m}$;

- Descending extension - a pilot hole from top to bottom is drilled, with subsequent top to bottom extension (descending). In this method, the diameter of the working is up to $1.5 \mathrm{~m}$ and the depth reached is up to $30 \mathrm{~m}$;

- Ascending extension - a pilot hole from bottom to top is drilled, with simultaneous side cutting to the full diameter of the extraction working. Rises of up to $2.5 \mathrm{~m}$ in diameter and up to $150 \mathrm{~m}$ in depth can be driven by this method.

B - Using mobile mechanization:

- Ascending driving - this method is intended for driving a compensation rise in mining systems in sub-level workings, sub-level caving and block caving systems.

The machine operates in workings with $4.5 \mathrm{~m} \times 4.5 \mathrm{~m}$ dimensions. This method allows a rise of up to $1.2 \mathrm{~m}$ in diameter and up to $200 \mathrm{~m}$ in length to be driven.

- Descending driving- the method is characterized by a top-down rise with a maximum diameter of $0.75 \mathrm{~m}$ and a length of up to $60 \mathrm{~m}$.

The drilling angle varies from $90^{\circ}$ to $60^{\circ}$ in all directions.

Knowing the capabilities of Raisebor mechanization provides the opportunity to use it as a mining mechanization - to develop an innovative technology for underground extraction of minerals, which strictly meets the specific requirements and characteristics of a given deposit.

It is important to note that the application of the Raisebor technology needs to be well-ensured from a 
geomechanical point of view. The geomechanical dimensioning will give the maximum open surfaces that can be naturally sustained. Hence, the specific dimensions of the mining blocks and their parameters should be determined, as well as the specific mechanization and method of driving the extraction workings.

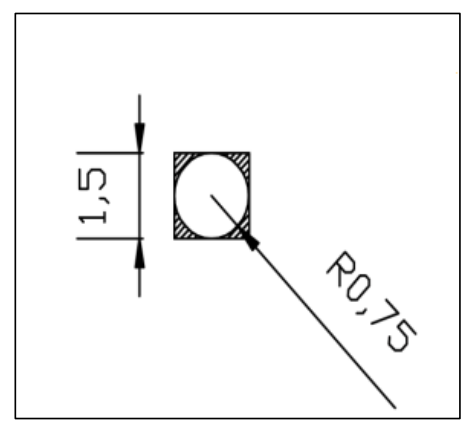

Fig. 2a. Raisebor technology for different diameters of the bit $\mathrm{R}=0,75 \mathrm{~m}$

$$
\begin{aligned}
& S_{1}=a^{2}=2,25 \mathrm{~m}^{2} \\
& S_{2}=\pi R^{2}=1,77 \mathrm{~m}^{2} \\
& S_{1}-S_{2}=0,48 \mathrm{~m}^{2} \\
& S_{1} / S_{2}=0,78
\end{aligned}
$$

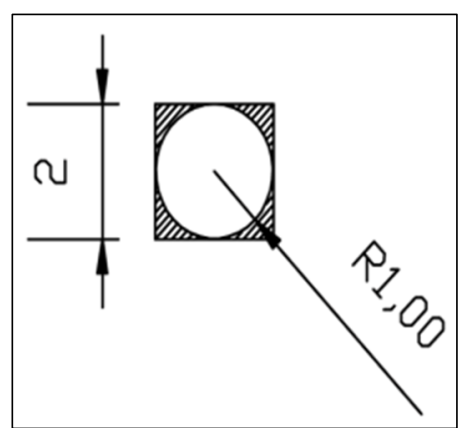

Fig. 2b. Raisebor technology for different diameters of the bit $\mathrm{R}=1,00 \mathrm{~m}$

$$
\begin{aligned}
& S_{1}=a^{2}=4,00 \mathrm{~m}^{2} ; \\
& S_{2}=\pi R^{2}=3,14 \mathrm{~m}^{2} \\
& S_{1}-S_{2}=0,86 \mathrm{~m}^{2} \\
& S_{1} / S_{2}=0,78
\end{aligned}
$$

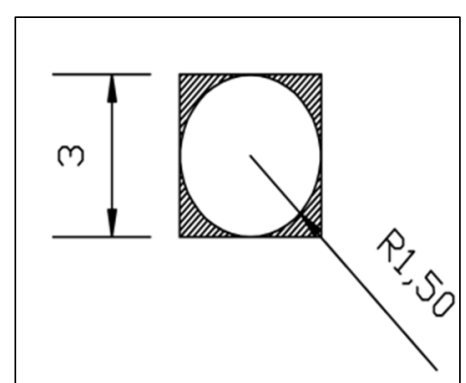

Fig. 2c. Raisebor technology for different diameters of the bit $\mathrm{R}=1,50 \mathrm{~m}$

The area ratios in the variant shown in Figure 2, $\mathrm{S}_{2} / \mathrm{S}_{1}$ for the five cases (a, b, c, d and e), show a mineral loss of

\section{Optimisation of the losses and contamination when using the Raisebor technology}

In order to ensure maximum recovery of the reserves using the Raisebor technology, different cases are considered for including the cutting head in ore bodies with thickness from 1.5 to $5 \mathrm{~m}$ (Fig. 2a, 2b, 2c, 2d, 2e).

$$
\begin{aligned}
& S_{1}=a^{2}=9,00 \mathrm{~m}^{2} ; \\
& S_{2}=\pi R^{2}=7,07 \mathrm{~m}^{2} ; \\
& S_{1}-S_{2}=1,93 \mathrm{~m}^{2} ; \\
& S_{1} / S_{2}=0,78
\end{aligned}
$$

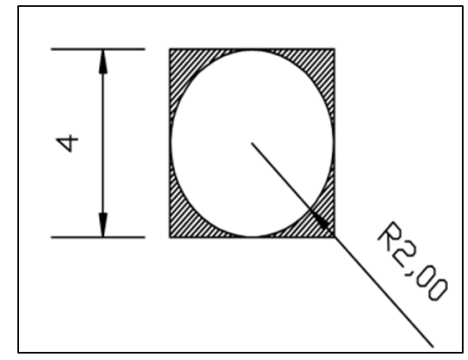

Fig. 2d. Raisebor technology for different diameters of the bit $\mathrm{R}=2,00 \mathrm{~m}$

$$
\begin{aligned}
& S_{1}=a^{2}=16,00 \mathrm{~m}^{2} \\
& S_{2}=\pi R^{2}=1,77 \mathrm{~m}^{2} \\
& S_{1}-S_{2}=0,48 \mathrm{~m}^{2} \\
& S_{1} / S_{2}=0,78
\end{aligned}
$$

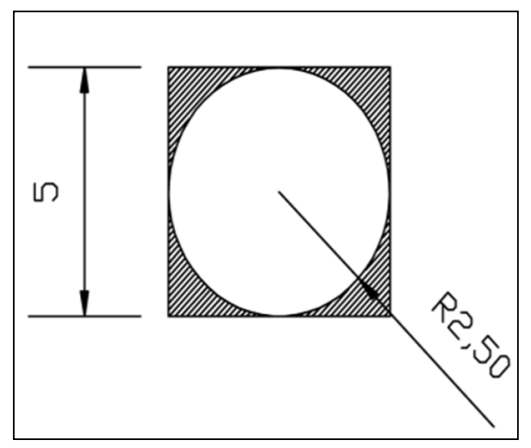

Fig. 2e. Raisebor technology for different diameters of the bit $\mathrm{R}=2,50 \mathrm{~m}$

$$
\begin{aligned}
& S_{1}=a^{2}=25,00 \mathrm{~m}^{2} \\
& S_{2}=\pi R^{2}=19,62 \mathrm{~m}^{2} \\
& S_{1}-S_{2}=5,38 \mathrm{~m}^{2} \\
& S_{1} / S_{2}=0,78
\end{aligned}
$$

$22 \%$ (the recovery ratio in this case is 0,78 ) or the contamination here is in the framework of the primary. 


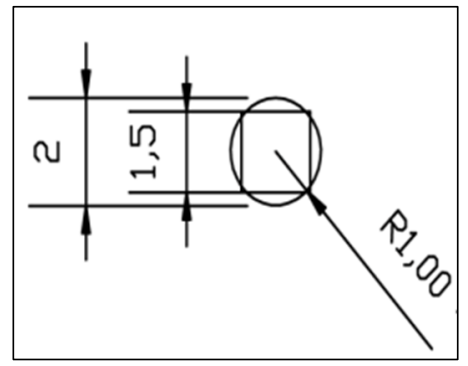

Fig. 3a. Raisebor technology with overlap of the contour $S_{1}=a^{2}=2,25 \mathrm{~m}^{2}$;

$S_{2}=\pi R^{2}=3,14 \mathrm{~m}^{2}$;

$S_{2} / S_{1}=1,39$

$S_{1} / S_{2}=0,72$

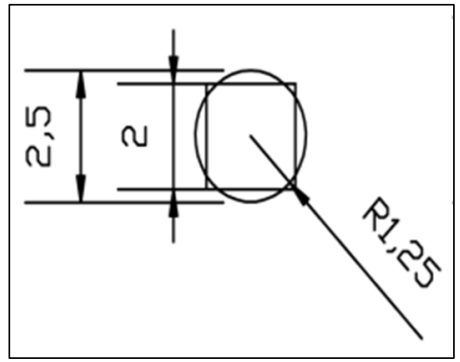

Fig. 3b. Raisebor technology with overlap of the contour

$$
\begin{aligned}
& S_{1}=a^{2}=4,00 \mathrm{~m}^{2} \\
& S_{2}=\pi R^{2}=4,91 \mathrm{~m}^{2} \\
& S_{2} / S_{1}=1,23 \\
& S_{1} / S_{2}=0,82
\end{aligned}
$$

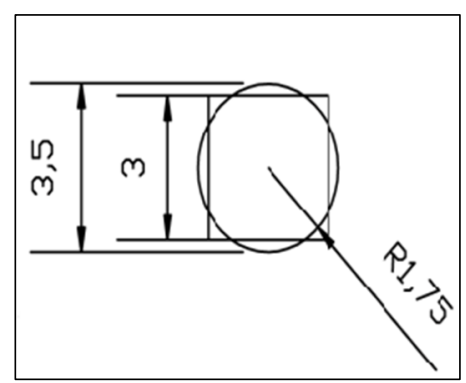

Fig. 3c. Raisebor technology with overlap of the contour

Table 1. Ratio diameter/thickness.

\begin{tabular}{|l|c|c|c|}
\hline No & $\begin{array}{c}\text { Ratio diameter of } \\
\text { recovery/thickness of } \\
\text { the ore body }\end{array}$ & $\begin{array}{c}\mathbf{R}_{\mathbf{0}} \\
\mathbf{\%}\end{array}$ & $\begin{array}{c}\mathbf{Z} \\
\mathbf{\%}\end{array}$ \\
\hline 1 & $2,0 / 1,5=1,33$ & 39 & 28 \\
\hline 2 & $2,5 / 2,0=1,25$ & 23 & 18 \\
\hline 3 & $3,5 / 3,0=1,17$ & 7 & 6 \\
\hline 4 & $4,7 / 4,0=1,18$ & 8 & 8 \\
\hline 5 & $6,0 / 5,0=1,20$ & 13 & 12 \\
\hline
\end{tabular}

In order to reduce the losses, Figure 3 shows variants with an increased area of the cutting head relative to the ore body.

On Figure 3a with an ore body thickness of $1,5 \mathrm{~m}$ the diameter of the cutting head of the Raisebor machine is set to $2 \mathrm{~m}$. In this configuration, the $\mathrm{S}_{2} / \mathrm{S}_{1}$ ratio $=1,39$ or $39 \%$ contamination and $\mathrm{S}_{1} / \mathrm{S}_{2}=0,72$ or $28 \%$ losses.

When the thickness of the ore body is $2,0 \mathrm{~m}$ and the diameter of the cutting head of the Raisebor machine is

$$
\begin{aligned}
& S_{1}=a^{2}=9,00 \mathrm{~m}^{2} \\
& S_{2}=\pi R^{2}=9,62 \mathrm{~m}^{2} \\
& S_{2} / S_{1}=1,07 \\
& S_{1} / S_{2}=0,94
\end{aligned}
$$

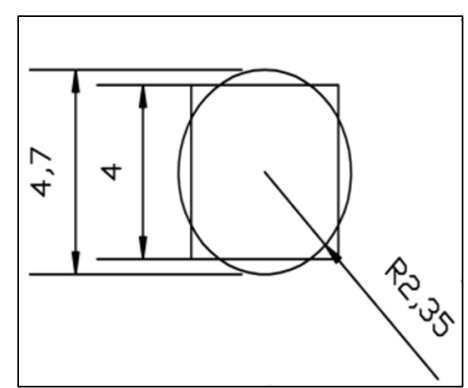

Fig. 3d. Raisebor technology with overlap of the contour

$$
\begin{aligned}
& S_{1}=a^{2}=16,00 \mathrm{~m}^{2} ; \\
& S_{2}=\pi R^{2}=17,34 \mathrm{~m}^{2} \\
& S_{2} / S_{1}=1,08
\end{aligned}
$$$$
S_{1} / S_{2}=0,92
$$

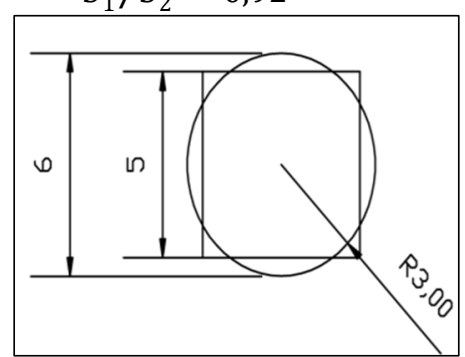

Fig. 3e. Raisebor technology with overlap of the contour

$$
\begin{aligned}
& S_{1}=a^{2}=25,00 \mathrm{~m}^{2} \\
& S_{2}=\pi R^{2}=28,26 \mathrm{~m}^{2} \\
& S_{2} / S_{1}=1,13 \\
& S_{1} / S_{2}=0,88
\end{aligned}
$$

$2.5 \mathrm{~m}$, the ratios are $\mathrm{S}_{2} / \mathrm{S}_{1}=1,23$ and contamination of $23 \%$ and $\mathrm{S}_{1} / \mathrm{S}_{2}=0,82$ and contamination of $18 \%$.

On Figure $3 \mathrm{c}$ with an ore body thickness of $3 \mathrm{~m}$, the diameter of the cutting head of the Raisebor machine is set to $3,5 \mathrm{~m}$. In this configuration, the $\mathrm{S}_{2} / \mathrm{S}_{1}$ ratio $=1,07$ or $7 \%$ contamination and $\mathrm{S}_{1} / \mathrm{S}_{2}=0,94$ or $6 \%$ losses.

For an ore body thickness of $4.0 \mathrm{~m}$ and a diameter of the cutting head of the Raisebor machine of $4,7 \mathrm{~m}$, the $\mathrm{S}_{2} / \mathrm{S}_{1}$ ratio $=1,18$ or $8 \%$ contamination and $\mathrm{S}_{1} / \mathrm{S}_{2}=0,92$ or $8 \%$ losses.

When the thickness of the ore body is $5 \mathrm{~m}$ and the diameter of the cutting head of the Raisebor machine is 6 $\mathrm{m}$, the $\mathrm{S}_{2} / \mathrm{S}_{1}$ ratio $=1,20$ or $13 \%$ contamination and $\mathrm{S}_{1} / \mathrm{S}_{2}$ $=0,88$ or $12 \%$ losses.

In order to reduce the damage from losses and contamination, it is recommended to observe the ratio $\mathrm{S}_{2} / \mathrm{S}_{1}$ from Figure 3c, which will determine the selection of the diameter of the cutting head of the Raisebor machine. 


\section{Raisebor technology using VCR method}

This method for mining out the mineral reserves combines the drilling and blasting works (VCR method) with the Raisebor technology. [9, 10] Here again, we have the extraction of vertical levels (rises) from the ore body in a certain order, with the mined-out spaces being filled. This method is characterized by mining out the primary chambers by applying drilling and blasting works. It is important to note that the complete drawing of the extracted ore from each layer takes place after its complete blasting. Until the blasting of the last section (VCR method), part of the ore remains in the layer (rise), thus ensuring its safety without the need for its further support. After drawing the ores off from the primary chambers, they are filled with a paste-hardening fill to achieve sufficient strength of the chamber in order to open a secondary chamber next to the filled-in rock mass without leaving behind pillars.

The secondary chambers are mined out using the Raisebor technology and after their removal, they can be filled with both a paste hardening fill and a rock fill of sterile mass.

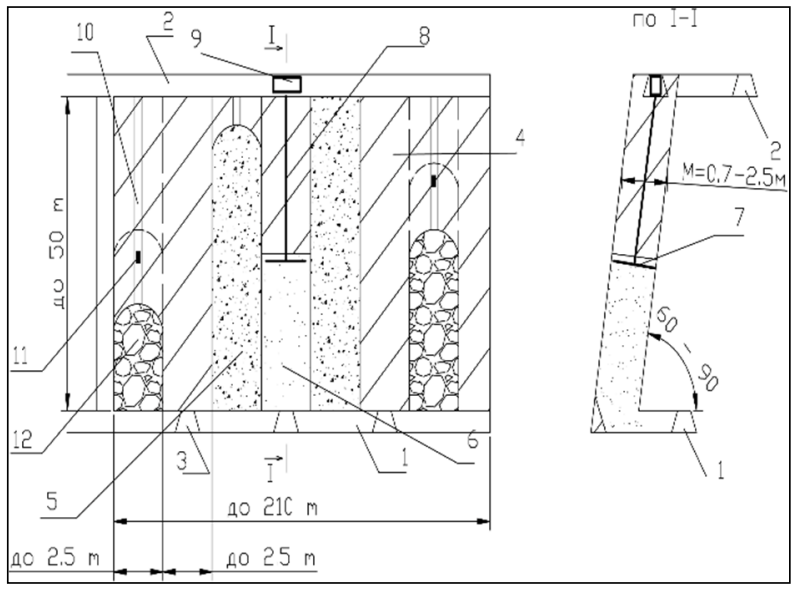

Fig. 4. Raisebor technology using the VCR method for extraction of mineral resources

Legend: 1 - haulage level; 2 - air drift; 3 - loading cut-off entries; 4 - ore body; 5 - paste-hardening fill; 6 - fines, extracted ore; 7 - cutting head; 8 - borehole; 9 - Raisebor machine; 10 central borehole; 11 - VCR method; 12 - blasted ore.

The Raisebor technology using the VCR method emphasizes again on security, since during both production stages (VCR method and Raisebor technology) the processes are carried out without the presence of workers in the mining areas.

The geomechanical dimensioning will give the maximum open surfaces that can be naturally supported as well as the dimensions of the primary and secondary chambers. From here, the specific sizes of the mining blocks and their parameters should be determined, as well as the order for removing the reserves.

\section{Continuous system for ore shrinkage and use of Alimak or KOV-25 monorail}

This is a classic variant of the continuous system for ore shrinkage, but the specifics is that it has been redesigned for the purpose of applying a productive technique, elimination of the manual labour, removal of people from the mining areas, and its application in rocks with low strength indicators.

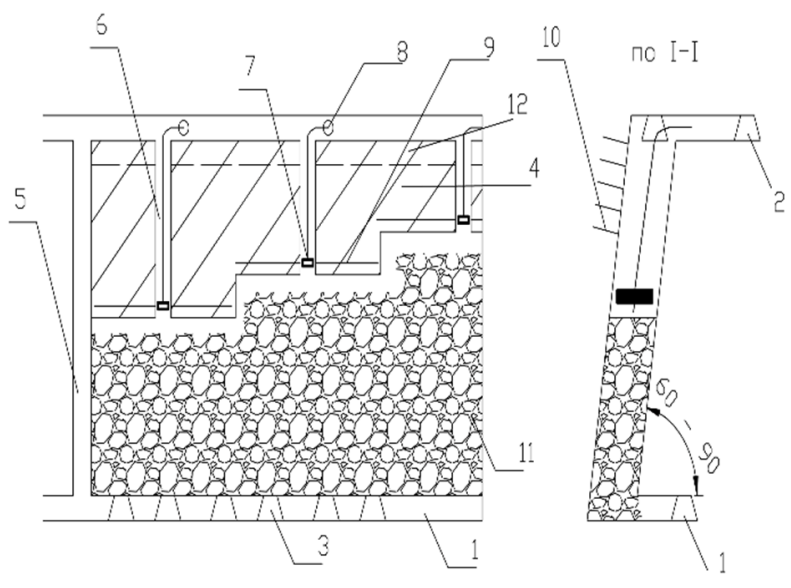

Fig. 5. Continuous system for ore shrinkage and use of Alimak or KOV-25 monorail complex

Legend: 1 - haulage level; 2 - air drift; 3 - loading cut-off entries; 4 - ore body; 5 - stope rise; 6 - cut rise; 7 - KOV-25 monorail complex; $8-$ a winch for hoses of the monorail complex; 9 - drilling boreholes; 10 - rock bolts; 11 - retained ore; 12 - sheet pillar.

In the continuous system with ore shrinkage and use of Alimak or KOV-25 monorail complex, the mining operations are performed by cut rises with horizontally positioned blast holes (horizontal layers are blasted). The use of monorail ore mining complexes significantly increases labour productivity - hydraulic mechanization is applied. Through this configuration of the block and the extraction of the cut rises, the work safety is ensured, with the workers being in pre-fixed workings. Therefore, greater safety at work is achieved and the cost of ancillary processes is also reduced.

Another important point that should be noted in this technology is its application in the development of deposits with weak ores and host rocks. In the variant presented, the retained ore is used to support the host rocks. By the time the ore is completely blasted from the block, the amount of ore that has been drawn off must be just enough to absorb the blasted ore from the next blast layer. After the blasting is completed, the ore is drawn off in parallel with the filling of the store. The fill in this case may be dry rock fill with material; obtained from preparatory activities. Thus, we have constant support, eliminating the risk of unwanted movements in the rock mass.

\section{Conclusion}

These innovative mining technologies aim at developing deposits with complex geological, mining technical and 
geomechanical characteristics. The aim is to provide sufficient labour safety, increased productivity, reduced loss rates and impoverishment during the mining process.

The presented innovative production technologies meet these requirements.

The advantages of implementing and using them in a particular mining company can significantly improve the processes for the following reasons:

1. The developed innovative technology for mining of mineral resources (shrinkage method of mining, filling and setting of rib pillars - Alimak technology) allows for recovery of reserves without pillars and with minimal losses and contamination during the mining process.

2. With the application of the VCR - Raisebor technology for mining of mineral resources when developing complex-structured and geothermal deposits, we achieve a high level of system safety.

3. It is important to take into account the specifics of the deposit itself and the characteristics of the ore bodies, and based on this to select the number and type of mechanization, as well as the order of mining.

4. When mining with the Raisebor technology, it is not necessary for the obtained ore fines (the extracted ore) to undergo coarse crushing - it is possible to eliminate additional processes and ensure direct feeding of the ore to the mineral processing plant for further processing. This leads to a significant reduction in production costs.

5. When applying the VCR-Raisebor technology for mining there is a considerable positive effect because the obtained rock mass from the development stages is used for filling in the secondary chambers. Thus, the haulage of the mining mass (ore and sterile body) is facilitated and the volumes of the waste dumps for sterile rock mass are considerably reduced.

6. By developing innovative technologies for mining, in particular VCR - Raisebor technology, we create an opportunity for safe and secure development of deposits with complex conditions and characteristics, previously considered to be economically not viable.

Geomechanical models should also be developed in order to identify open surfaces that can naturally be supported. Thus, the specific parameters of the selected extraction technology such as height of levels, presence of sub-levels, dimensions of blasted layers, etc. could be determined.

\section{References}

1. D. Anastasov, N. Valkanov, L. Totev, G. Dachev, I. Mitev, Geomechanical dimensioning and implementation of innovative systems for mining out of vein deposits. Paper presented at the 25 th World Mining Congress, Astana, Kazakhstan, 19-22 June 2018

2. B.W. Jamieson, Mining the high grade MacArthur River uranium deposit, (International Atomic Energy
Agency, Vienna, Austria, OECD Nuclear Energy Agency, Paris, France, Nuclear Energy Institute, Washington DC, United States, World Nuclear Association, London, United Kingdom, Office of the Supervising Scientist Environment, Darwin, Australia, 2002)

3. S. Pysmennyi, M. Fedko, N. Shvaler, S. Chukharev, Mining of rich iron ore deposits of complex structure under the condition of rock pressure development. E3S Web of Conferences, $01022 \quad$ (2020) https://doi.org/10.1051/e3sconf/2020201001022

4. M.B. Fedko, I.O. Muzyka, S.V. Pismennyi \& O.V. Kalinichenko, Determination of drilling and blasting parameters considering the stress-strain state of rock ores. Naukovyi Visnyk Natsionalnoho Hirnychoho
Universytetuq
(1), 37-41,
(2019)

https://doi.org/10.29202/nvngu/2019-1/20

5. www.epiroc.com Accessed 15 Nov 2020

6. Raiseboring Equipment. www.sandvic.com Accessed 9 Mart 2017

7. G. Dachev, D. Stefanov, Assessment and analysis methodology for the dimensioning of isolated rib pillars, Paper presented at VIth Scientific and Technical Conference with International Participation Technologies and Practices in Underground Mining and Mine Construction, Devin, Bulgaria, 1-4 October 2018

8. Raise boring slots\& a modern mining technique. Mining World 13(2), (2016)

9. V.L. Baron, V.H. Kantor, Technique and technology for blasting works in USA, (Nedra, 1989)

10. C.W. Livingston U.S. Patent 3,762,771, 2 Oct 1973 